\title{
Similar protein expression profiles of ovarian and endometrial high-grade serous carcinomas
}

\author{
Kosuke Hiramatsu ${ }^{1,2}$, Kiyoshi Yoshino*,1, Satoshi Serada ${ }^{2}$, Kosuke Yoshihara ${ }^{3}$, Yumiko Hori ${ }^{4}$, Minoru Fujimoto ${ }^{2}$, \\ Shinya Matsuzaki ${ }^{1}$, Tomomi Egawa-Takata ${ }^{1}$, Eiji Kobayashi ${ }^{1}$, Yutaka Ueda ${ }^{1}$, Eiichi Morii ${ }^{4}$, Takayuki Enomoto ${ }^{3}$, \\ Tetsuji Naka ${ }^{2}$ and Tadashi Kimura ${ }^{1}$ \\ ${ }^{1}$ Department of Obstetrics and Gynecology, Osaka University Graduate School of Medicine, 2-2, Yamadaoka, Suita, \\ Osaka 565-0871, Japan; ${ }^{2}$ Laboratory of Immune Signal, National Institute of Biomedical Innovation, Health and Nutrition, 7-6-8, \\ Saito-Asagi, Ibaraki, Osaka 567-0085, Japan; ${ }^{3}$ Department of Obstetrics and Gynecology, Niigata University Graduate School of \\ Medical and Dental Sciences, 757, Ichibancho, Asahimachidori, Chuo-ku, Niigata, Niigata 951-8510, Japan and ${ }^{4}$ Department of \\ Pathology, Osaka University Graduate School of Medicine, 2-2, Yamadaoka, Suita, Osaka 565-0871, Japan
}

Background: Ovarian and endometrial high-grade serous carcinomas (HGSCs) have similar clinical and pathological characteristics; however, exhaustive protein expression profiling of these cancers has yet to be reported.

Methods: We performed protein expression profiling on 14 cases of HGSCs (7 ovarian and 7 endometrial) and 18 endometrioid carcinomas (9 ovarian and 9 endometrial) using iTRAQ-based exhaustive and quantitative protein analysis.

Results: We identified 828 tumour-expressed proteins and evaluated the statistical similarity of protein expression profiles between ovarian and endometrial HGSCs using unsupervised hierarchical cluster analysis $(P<0.01)$. Using 45 statistically highly expressed proteins in HGSCs, protein ontology analysis detected two enriched terms and proteins composing each term: IMP2 and MCM2. Immunohistochemical analyses confirmed the higher expression of IMP2 and MCM2 in ovarian and endometrial HGSCs as well as in tubal and peritoneal HGSCs than in endometrioid carcinomas $(P<0.01)$. The knockdown of either IMP2 or MCM2 by siRNA interference significantly decreased the proliferation rate of ovarian HGSC cell line $(P<0.01)$.

Conclusions: We demonstrated the statistical similarity of the protein expression profiles of ovarian and endometrial HGSC beyond the organs. We suggest that increased IMP2 and MCM2 expression may underlie some of the rapid HGSC growth observed clinically.

High-grade serous carcinoma (HGSC) is the most common histological subtype of ovarian cancer, accounting for $70 \%$ of such cases (Kurman, 2013). The majority of patients with ovarian HGSC are post menopausal and are usually diagnosed at a late stage, at a substantial period of time after metastasis (Gross et al, 2010). The pathological features of ovarian HGSCs are pleomorphic and marked nuclear atypia with a high mitotic index (Malpica et al, 2004). At the molecular level, ovarian HGSCs typically show a high frequency of TP53 and PIK3CA gene mutations (Ab Mutalib et al, 2014). In a recent report, a $B C A M$ and $A K T 2$ fusion gene (which activates AKT2 kinase) was observed in 7\% of ovarian HGSC cases (Kannan et al, 2015). Serous tubal intraepithelial carcinoma (STIC) has been posited as a precursor lesion of ovarian HGSC (Gross et al, 2010). Serous tubal intraepithelial carcinoma shares similar pathological and molecular features with ovarian HGSC, including atypical nuclei and TP53 mutations (Salvador et al, 2008).

Endometrial cancer can be categorised into two groups: type I, oestrogen-dependent tumours, including endometrioid carcinoma, and type II, oestrogen-independent tumours, including HGSC and clear cell carcinoma. Type II endometrial HGSC typically

*Correspondence: Dr K Yoshino; E-mail: yoshino@gyne.med.osaka-u.ac.jp

Received 29 July 2015; revised 9 December 2015; accepted 20 January 2016; published online 18 February 2016

(c) 2016 Cancer Research UK. All rights reserved 0007-0920/16 
demonstrates a greater degree of myometrial invasion and lymphovascular involvement compared with type I endometrial carcinoma (del Carmen et al, 2012), with more aggressive clinical behaviour (Cao et al, 2004; Soslow et al, 2007). At the molecular level, higher frequencies of TP53 and PIK3CA mutations have been demonstrated in type II endometrial HGSC (Kandoth et al, 2013). Endometrial intraepithelial carcinoma (EIC), posited to be a precursor lesion of endometrial HGSC (Sherman et al, 1992; Zheng and Schwartz, 2005), was first described in 1992 by Sherman et al (1992). Endometrial intraepithelial carcinoma is defined as the replacement of endometrial epithelium and glands without myometrial invasion or lymphovascular involvement (Zheng and Schwartz, 2005). Endometrial HGSC and EIC also share similar molecular features, including frequent TP53 mutation (Pathiraja et al, 2013).

As described above, ovarian and endometrial HGSCs have similar clinical and pathological characteristics, with intraepithelial carcinoma considered to be a potential precursor lesion to both tumour subtypes. In the present study, we aimed to assess the degree of molecular similarity between ovarian and endometrial HGSC, beyond just the known TP53 mutations.

One of the hallmark events in ovarian tumourigenesis is the transition of benign precursor lesions into advanced metastatic tumours through molecular mechanisms that remain poorly understood. The identification of molecular markers for different tumour cell populations allows for the correct differential diagnosis of subtypes of malignant invasive tumours - a critical component in the development of more effective diagnostic and therapeutic strategies for cancer treatments. The cDNA microarray analysis of mRNA expression has been frequently used to identify new targets in cancer for diagnosis, and for predicting prognosis and treatment responses to specific therapies (Macoska, 2002).

Several recent studies have investigated expression profiles of ovarian and endometrial cancers using cDNA microarrays (Santin et al, 2004; Zorn et al, 2005; Kandoth et al, 2013). The comparison study of mRNA expression profiles by Zorn et al (2005) found no statistical similarity between ovarian and endometrial serous carcinomas. However, their cluster analysis was limited because they compared only the differences between ovarian and endometrial serous carcinomas without including other histological types of ovarian and endometrial cancer. Moreover, steady-state mRNA levels are frequently found to not correspond linearly with protein levels because of the highly variable translation rates of some mRNAs, and to vastly variable differences in mRNA and protein half-lives (Chen et al, 2002; Tian et al, 2004).

Although they are more technically challenging to conduct, analytical comparisons of actual protein expression profiles are required. Recent developments in proteomics, such as liquid chromatography tandem mass spectrometry (LC-MS/MS) for qualitative and semiquantitative shotgun proteomics, can now be applied to the systematic determination of tumour cell proteomes.

In this study, we have performed protein expression profiling using iTRAQ-based exhaustive and quantitative protein analysis to evaluate the similarity of protein expression profiles between ovarian and endometrial HGSCs. We conducted an unsupervised hierarchical cluster analysis to determine the statistical similarity between the identified protein profiles. Furthermore, we identified enriched protein functional 'terms' in HGSC by protein ontology analysis and analysed the in vitro functions of two shared highly overexpressed proteins.

\section{MATERIALS AND METHODS}

Tissue samples. Written informed consent was obtained from all patients and the experimental protocol was approved by the Ethics
Committees of the Osaka University and the National Institute of Biomedical Innovation, Health and Nutrition of Japan. Patient characteristics are shown in Table 1. Diagnoses of HGSC and grade 1 endometrioid carcinoma (EC) were confirmed by central pathology review.

Fresh-frozen samples of 32 cancers (7 ovarian HGSCs, 7 endometrial HGSCs, 9 ovarian ECs and 9 endometrial ECs) were used in the present study. Small pieces of tissue samples were immersed in OCT compound (Sakura Finetek, Torrance, CA, USA), frozen in liquid $\mathrm{N}_{2}$ and stored at $-80^{\circ} \mathrm{C}$. Serial $16 \mu \mathrm{m}$ thick sections of samples were mounted at $-20^{\circ} \mathrm{C}$ onto PETmembrane slides (Leica Biosystems, Nussloch, Germany) using a Cryostat HTRAX C50 (Thermo Fisher, Waltham, MA, USA). Fixation and staining of sections by Mayer's haematoxylin solution (Wako Pure Chemical Industries, Osaka, Japan) were performed as previously described (Kondo and Hirohashi, 2006). To exclude stromal cells, cancer cells were captured by LMD using a light microscope (DM 6000B; Leica Microsystems, Wetzlar, Germany) and transferred into a tube cap, according to the manufacturer's instructions. For protein extraction, samples were incubated in $98 \mu \mathrm{l}$ of $9.8 \mathrm{M}$ urea, $1 \mu \mathrm{l}$ of phosphatase inhibitor cocktail (Nacalai Tesque, Kyoto, Japan), $1 \mu$ l of protease inhibitor cocktail (Nacalai Tesque) and $0.5 \mu \mathrm{l}$ of benzonase (Calbiochem, San Diego, CA, USA) for $30 \mathrm{~min}$ at room temperature. Approximately $20-100 \mu \mathrm{g}$ of protein was obtained per sample following centrifugation at 15000 r.p.m. at $10^{\circ} \mathrm{C}$ for $10 \mathrm{~min}$.

Cell lines. The human ovarian serous carcinoma cell lines OVSAHO and KURAMOCHI, and the human endometrial carcinoma cell line HEC265, were obtained from the Japanese Collection of Research Bioresources (Osaka, Japan). All cell lines were tested and authenticated. OVSAHO and KURAMOCHI cells were maintained in RPMI-1640 medium (Wako Pure Chemical Industries) supplemented with 10\% FBS (Serum Source International, NC, USA) and $1 \%$ penicillin-streptomycin (Nacalai Tesque). The HEC265 cells were maintained in DMEM (Wako Pure Chemical Industries) supplemented with 10\% FBS (Serum Source International), $100 \mathrm{U} \mathrm{ml}^{-1}$ penicillin and $100 \mu \mathrm{g} \mathrm{ml}^{-1}$ streptomycin (Nacalai Tesque). Cells were cultured at $37^{\circ} \mathrm{C}$ under a humidified atmosphere of $5 \% \mathrm{CO}_{2}$.

For protein extraction, OVSAHO and HEC265 cells were incubated in $98 \mu \mathrm{l}$ of $9.8 \mathrm{M}$ urea, $1 \mu \mathrm{l}$ of phosphatase inhibitor cocktail and $1 \mu \mathrm{l}$ of protease inhibitor cocktail for $30 \mathrm{~min}$ at room temperature before centrifugation at 15000 r.p.m. for $10 \mathrm{~min}$ at $10{ }^{\circ} \mathrm{C}$.

'Cell line samples' were prepared by combining equal amounts of protein extracted from ovarian OVSAHO and endometrial HEC265 tumour cell lines. 'Cell line samples' were used as reference baselines for analysis of protein expression data.

iTRAQ labelling. Tissue samples and 'cell line samples' were prepared using iTRAQ reagent according to the manufacturer's instructions (AB SCIEX, Framingham, CA, USA). In each iTRAQ

\begin{tabular}{|c|c|c|c|c|}
\hline & \multicolumn{2}{|c|}{ HGSC } & \multicolumn{2}{|c|}{ EC } \\
\hline & Ovarian & Endometrial & Ovarian & Endometrial \\
\hline $\begin{array}{l}\text { No. of cases } \\
\text { Age, median (range) }\end{array}$ & $\begin{array}{c}7 \\
65(53-80)\end{array}$ & $\begin{array}{c}7 \\
71(61-77)\end{array}$ & $\begin{array}{c}9 \\
41(32-79)\end{array}$ & $\begin{array}{c}9 \\
59(39-81)\end{array}$ \\
\hline \multicolumn{5}{|l|}{ FIGO stage } \\
\hline $\begin{array}{l}\text { I } \\
\text { II } \\
\text { III } \\
\text { IV }\end{array}$ & $\begin{array}{l}1 \\
1 \\
4 \\
1\end{array}$ & $\begin{array}{l}2 \\
1 \\
4 \\
0\end{array}$ & $\begin{array}{l}5 \\
3 \\
1 \\
0\end{array}$ & $\begin{array}{l}7 \\
1 \\
1 \\
0\end{array}$ \\
\hline $\begin{array}{l}\text { Abbreviations: } \mathrm{EC}=\text { gra } \\
\text { Gynaecology and Obste }\end{array}$ & $\begin{array}{l}\text { endometr } \\
\text { HGSC }=1\end{array}$ & $\begin{array}{l}\text { id carcinoma; FIC } \\
\text { gh-grade serous }\end{array}$ & $\begin{array}{l}=\text { Internati } \\
\text { cinoma. }\end{array}$ & hal Federation of \\
\hline
\end{tabular}


series, tissue samples were labelled with iTRAQ reagents 113,114 , $115,116,117$ and 118, respectively. Individual 'cell line samples' were separately labelled with reagent 119 or 121 . Labelled samples were then pooled, desalted and fractionated by strong cation exchange chromatography as previously described (Yokoyama et al, 2013). Six series of iTRAQ labelling were performed.

Mass spectrometric analysis. Nano LC-MS/MS analyses were performed on an LTQ-Orbitrap XL mass spectrometer (Thermo Fisher Scientific, Waltham, MA, USA) as previously described (Yokoyama et al, 2013).

iTRAQ data analysis. Protein identification and quantification by iTRAQ analysis was performed using Proteome Discoverer software (v. 1.3, Thermo Fisher Scientific) and the SwissProt human protein database (SwissProt_2012_03; 536489 entries). Taxonomy was set to Homo sapiens (20329 entries) or mammalian (65888 entries). Search parameter conditions were as previously described (Yokoyama et al, 2013). The mass spectrometry proteomic data have been deposited in the ProteomeXchange Consortium database, via the PRIDE partner repository, with the data set identifier PXD001849. Protein expression data of tissue samples were obtained using the reagent 119-labelled 'cell line sample' as a reference. Six series of iTRAQ labellings were combined. To remove 'noise' in the data from iTRAQ experiments, we calculated the s.d. for all proteins in the reagent 121-labelled 'cell line sample' from the six labelling experiments. Thirty-nine proteins were excluded with s.d. values of $>99$ th percentile. Next, we performed median normalisation in all samples and identified 356 proteins variably expressed across samples based on s.d. values of $>0.3$.

Unsupervised hierarchical cluster analysis and protein ontology analysis. Unsupervised hierarchical cluster analysis was performed using Pearson's correlation and average linkage. To identify core samples in each cluster, silhouette-width values were calculated for all samples. Silhouette width was defined as the ratio of the average distance between the sample and other samples in the same cluster to the smallest distance between the sample and other samples in a different cluster. Only samples with positive silhouette values were used in subsequent analyses.

Ontology analysis was performed using the Database for Annotation, Visualization and Integrated Discovery (DAVID) (http://david.abcc.ncifcrf.gov/) for protein expression data. 'Homo sapiens' was used as the background set. $P$-values for ontology analysis were adjusted using the Benjamini-Hochberg false discovery rate (FDR) as the control for multiple hypothesis testing to correct for multiple comparisons (Huang et al, 2009).

Immunohistochemistry. Sections of $4 \mu \mathrm{m}$ width were prepared from formalin-fixed, paraffin-embedded tissue specimens, then deparaffinised and rehydrated using standard methods. Immunohistochemical (IHC) staining for IMP2 was performed using a mouse monoclonal anti-IMP2 antibody (GeneTex, Irvine, CA, USA) and a ChemMate ENVISION kit/HRP (DAB)-universal kit (K5007; Dako, Copenhagen, Denmark) according to the manufacturer's instructions. Immunohistochemical staining for MCM2 was performed using a rabbit polyclonal anti-MCM2 antibody (Atlas Antibodies, Stockholm, Sweden); the same secondary reagents were used for IMP2 immunohistochemistry. Immunohistochemical analysis was also performed on placental tissue and normal ovarian epithelium as the positive control and negative control, respectively. Stained sections were photographed using an Olympus FSX100 (Olympus, Tokyo, Japan). Quantitative evaluations were performed according to the intensity and distribution of immunohistochemical staining as follows: $0+$, no cells stained; $1+$, pale staining observed in any cells; $2+$, deeply stained cells covering $<25 \%$ of the total area; $3+$, deeply stained cells covering $25-49 \%$ of the total area; or $4+$, deeply stained cells covering $>50 \%$ of the total area. Samples were divided into the low expression group (samples with scores of $0+, 1+$ and $2+$ ) or the high expression group (scores of $3+$ and $4+$ ).

Transfection of siRNA and western blotting. The KURAMOCHI cells were seeded in 12-well plates at a density of $8 \times 10^{4}$ cells per well in $1 \mathrm{ml}$ of RPMI-1640 medium supplemented with $10 \%$ FBS. The IMP2 or MCM2 siRNA (Dharmacon, Lafayette, CO, USA) were transfected into KURAMOCHI cells using Lipofectamine RNAiMAX (Life Technologies, Carlsbad, CA, USA). Cells were harvested after $72 \mathrm{~h}$. Extracted proteins were resolved by SDS-PAGE and transferred onto a polyvinylidene difluoride membrane as previously described (Iwahori et al, 2011). The following primary antibodies were used for western blotting analysis: anti-IMP2 (GeneTex), anti-MCM2 (Atlas Antibodies) and anti- $\beta$-actin (A5441) (Sigma-Aldrich, St Louis, MO, USA).

Transfection of siRNA and cell proliferation assay. At 1 day before transfection, KURAMOCHI cells were seeded in 96-well plates at a density of 1000 cells per well in $100 \mu \mathrm{l}$ of RPMI-1640 medium supplemented with $10 \%$ FBS. The IMP2 or MCM2 siRNAs were transfected into KURAMOCHI cells using the same methodology as described above. Media were changed $24 \mathrm{~h}$ after siRNA transfection. At $96 \mathrm{~h}$ hours after media exchange, cell proliferation was assessed by a WST-8 assay as previously described (Yokoyama et al, 2013).

Cell cycle assay. The IMP2 siRNA-transfected KURAMOCHI cells were seeded in 6-well plates at a density of $1.5 \times 10^{5}$ cells per well. After $48 \mathrm{~h}$, cell cycle analysis was performed using a FACSCanto II cytometer (Becton Dickinson, San Jose, CA, USA). Cell cycle analysis was carried out in triplicate as previously described (Iwahori et al, 2011).

Statistical analyses. Student's $t$-test was used for comparisons between two groups. Data are presented as the mean \pm s.d. Differences in IMP2 and MCM2 expression distributions between HGSC and EC were analysed by Fisher's exact test. $P$-values of $<0.05$ were considered statistically significant.

\section{RESULTS}

Protein expression analysis and unsupervised hierarchical cluster analysis. A total of 828 tumour-expressed proteins were identified from a series of six iTRAQ labelling experiments. Of these 828 proteins, 356 proteins were variably expressed across all samples, with s.d. values $>0.3$. These 356 proteins were included in an unsupervised hierarchical cluster analysis. Two major clusters, $\mathrm{A}$ and $\mathrm{B}$, were identified in the resulting dendrogram (Figure 1). To classify the two clusters, the tumour histological type (HGSC or EC) and organ (ovary or endometrium) of each sample in each cluster were analysed following identification of core samples using silhouette-width values. When evaluating histological type, 14 of the 16 samples in cluster A were identified as ECs, and 7 of the 8 samples in cluster B were identified as HGSCs $(P<0.01$; Table 2). However, when evaluating 'organs', 10 of 16 samples in cluster A were found to be from endometrial cancers, and 4 of 8 in cluster $\mathrm{B}$ were found to be from ovarian cancers $(P=0.6734$; Table 2$)$. These results suggest that the criteria for the classification of the two clusters by protein expression profile were their histological type, that is, profile clusters $A$ and $B$ were organised by EC and HGSC types, respectively. Taken together, the protein expression profiles obtained in the present study demonstrate a strong statistical similarity between ovarian and endometrial HGSCs that belies their organs.

Protein ontology analysis. To evaluate enriched functional terms related to variably expressed proteins in HGSC, we performed ontology analysis using DAVID. Of the 356 proteins 


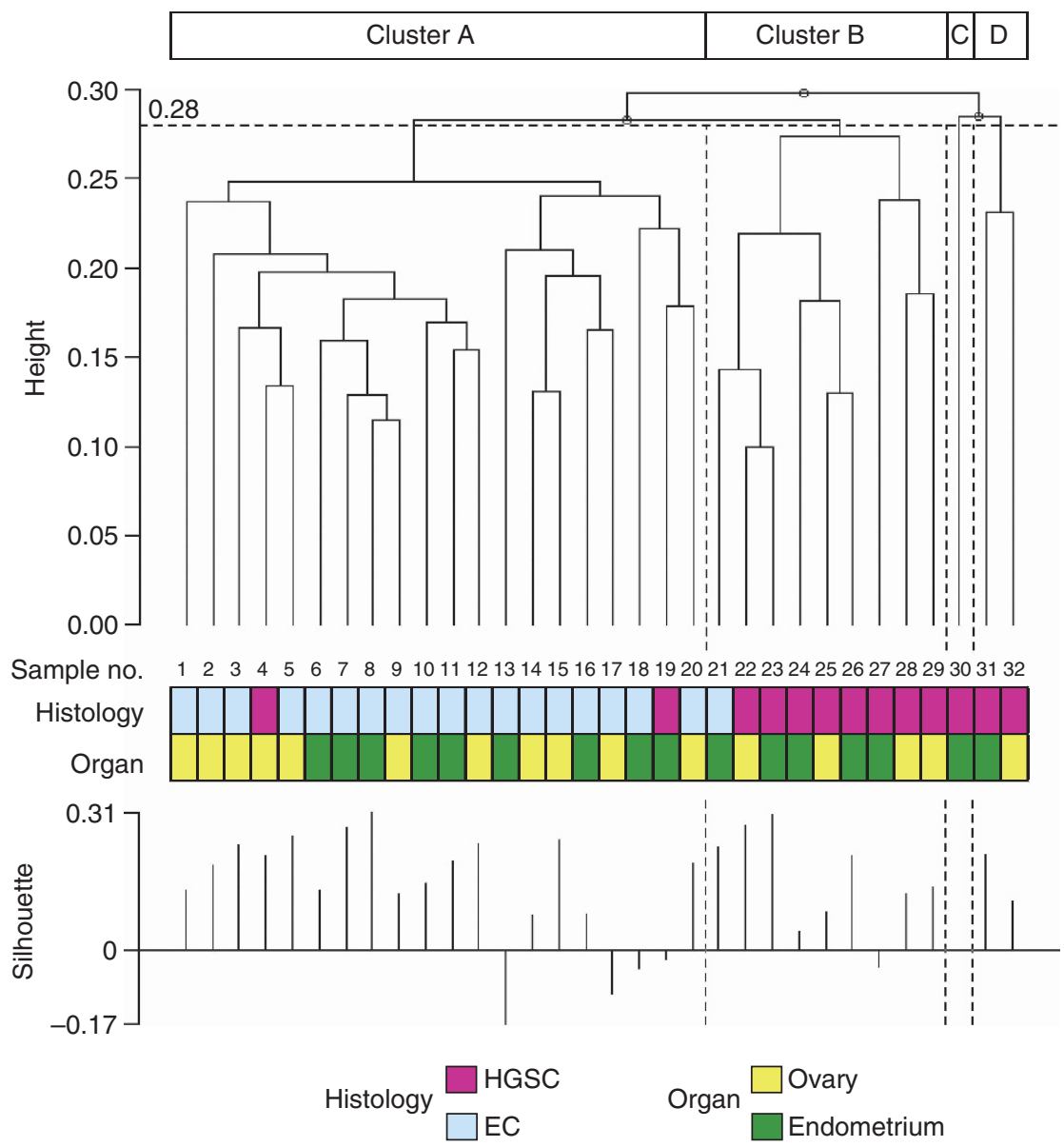

Figure 1. Dendrogram produced by unsupervised hierarchical cluster analysis of tissue samples. Two major clusters were identified: clusters $A$ and B. In the histology bar, samples of HGSCs and ECs are shown in red and green, respectively. In the organ bar, ovarian and endometrial cancers are shown in yellow and blue, respectively. The characteristics of each tissue sample are shown in Supplementary Table S2.

Table 2. Classification of clusters $A$ and $B$

\begin{tabular}{|c|c|c|c|}
\hline & Cluster A & Cluster B & $P$-value \\
\hline \multicolumn{4}{|l|}{ Histology } \\
\hline HGSC & 2 & 7 & \multirow[t]{2}{*}{0.0007} \\
\hline EC & 14 & 1 & \\
\hline \multicolumn{4}{|l|}{ Organ } \\
\hline Ovary & 6 & 4 & \multirow[t]{2}{*}{0.6734} \\
\hline Endometrium & 10 & 4 & \\
\hline \multirow[t]{2}{*}{ Total } & 16 & 8 & \\
\hline & & \multicolumn{2}{|c|}{ (Fisher's exact test) } \\
\hline
\end{tabular}

Abbreviations: $\mathrm{EC}=$ grade 1 endometrioid carcinoma; $\mathrm{HGSC}=$ high-grade serous carcinoma. In cluster $\mathrm{A}$, by histological type, 14 of 16 tumour samples were $\mathrm{ECs}$ and only 2 were HGSCs. In cluster $B, 7$ of 8 samples were HGSCs and only 1 was EC $(P=0.0007)$. However, by organs, in cluster $A, 10$ of the 16 samples were from endometrial cancer and 6 of 10 were ovarian cancer. In cluster $\mathrm{B}, 4$ of 8 samples were ovarian cancer and 4 were endometrial cancer $(P=0.6734)$.

with statistically higher expression in HGSC (Figure 2 and Supplementary Table S1), 45 were selected for further analysis. Protein ontology analysis identified two enriched 'terms' in HGSC: 'negative regulation of metabolic process' $(q=0.15)$ and 'DNA replication initiation' $(q=0.29$; Table 3$)$. Six differentially expressed proteins were found to be involved in 'negative regulation of metabolic process' and three in 'DNA replication initiation' (Table 3). The IMP2 and MCM2 were the most differentially expressed proteins related to 'negative regulation of metabolic process' and 'DNA replication initiation', respectively, with mean expression ratios between HGSC and EC of 2.691 and 1.549 , respectively (Table 3 ).

Immunohistochemistry. To confirm the high differential expression of IMP2 and MCM2 in ovarian and endometrial HGSC tumour cells, IHC analyses were performed using paraffinembedded tissue samples. The IHC staining of IMP2 and MCM2 in tissue sections revealed significantly greater IMP2 and MCM2 staining in HGSC samples compared with EC samples $(P<0.01$ and $P<0.01$, respectively; Figure 3 and Table 4$)$. In addition, stronger IMP2 and MCM2 staining (10 out of 10 (100\%) and 10 out of $10(100 \%)$, respectively) was observed in tubal cancers, and likewise in peritoneal HGSC samples (IMP2 8 out of 8 (100\%) and MCM2 7 out of $8(88 \%)$ ) (Supplementary Figure S1), indicating increased IMP2 and MCM2 protein expression may be a common feature of pelvic HGSC.

The effects of IMP2 and MCM2 in cell proliferation. To analyse the effect of IMP2 expression on cellular proliferation in HGSC, the effect of IMP2 knockdown was evaluated in KURAMOCHI cells using siRNA transfection. The IMP2 siRNA transfection led to significantly decreased IMP2 expression levels (Figure 4A) and cell proliferation assays demonstrated significantly decreased cell proliferation as compared with control siRNA $(P<0.01$; Figure 4B). The MCM2 siRNA transfection resulted in significantly decreased proliferation of KURAMOCHI cells as well $(P<0.01$; Figure $4 \mathrm{~B}$ ). These results demonstrate that the increased expression of IMP2 and/or MCM2 may be leading to the increased cell proliferation of HGSC. 


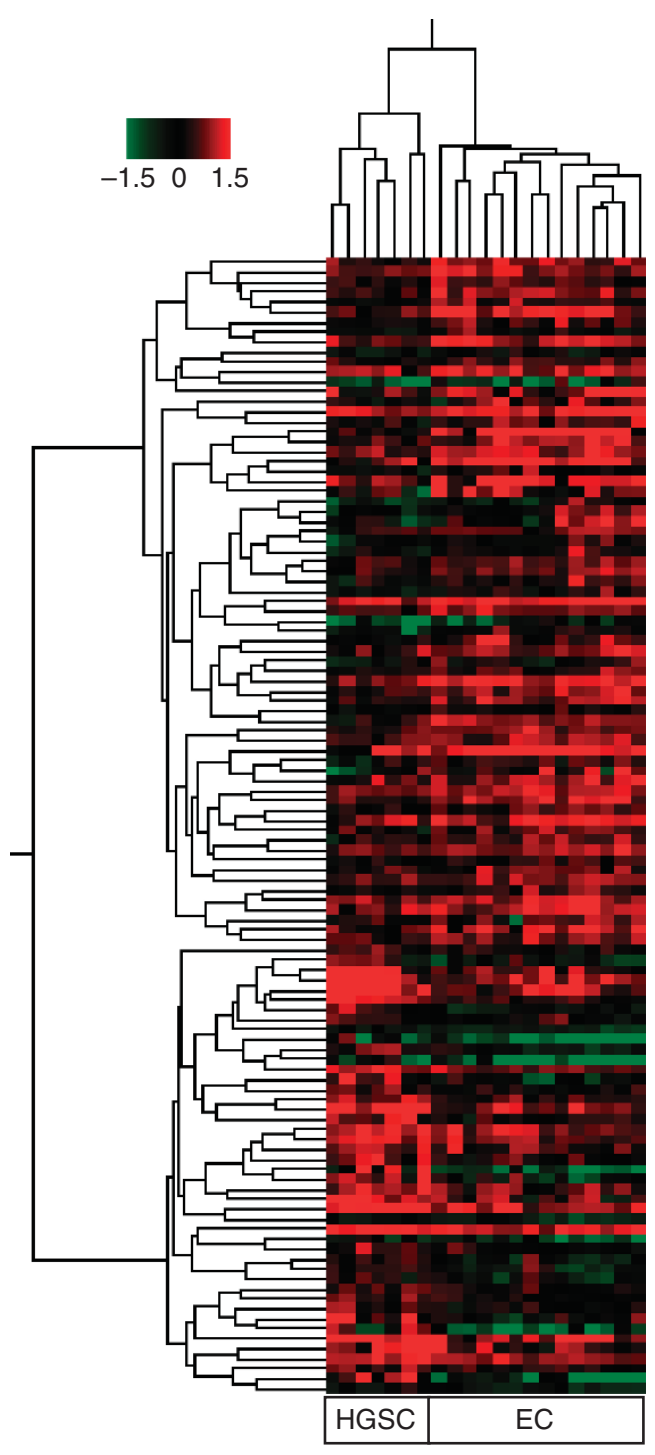

Figure 2. Differential protein expression profiles of 7 HGSC and 14 EC samples. The expression level of each protein is coloured; red represents expression above the mean and green indicates expression below the mean. Of the 356 proteins with statistically higher expression in HGSC, 45 are located in the lower section.

The effect of IMP2 in cell cycle. To analyse the function of IMP2 on cell cycle in ovarian HGSC, we performed cell cycle analysis using IMP2 siRNA-transfected KURAMOCHI cells. Fluorescenceactivated cell sorting (FACS) analysis revealed that the knockdown of IMP2 significantly increased G0/G1 cell population and decreased S-phase cell population $(P<0.01$, respectively; Figure $4 \mathrm{C}$ ). These data show that IMP2 contributes to regulating cell cycle and subsequent cellular proliferation.

\section{DISCUSSION}

In the present study, we have demonstrated a striking similarity between the protein expression profiles of ovarian and endometrial HGSCs using iTRAQ-based exhaustive and quantitative protein analysis and unsupervised hierarchical cluster analysis. To our knowledge, this is the first such proteomics report of protein expression profiling of HGSC from multiple organs demonstrating the statistical similarity of HGSC with differing organs. There are as yet few reports of exhaustive protein expression profiling in cancers other than gynaecological types.
Table 3. Enriched functional terms and proteins organising them in HGSCs

\begin{tabular}{|c|c|}
\hline Terms and proteins & $\begin{array}{c}\text { HGSC/EC } \\
\text { ratio }\end{array}$ \\
\hline \multicolumn{2}{|l|}{ Negative regulation of protein metabolic process } \\
\hline $\begin{array}{l}\text { Insulin-like growth factor } 2 \text { mRNA-binding protein } 2 \\
\text { (IMP2) } \\
\alpha 2-\text { Macroglobulin } \\
\text { Proteasome activator complex subunit } 1 \\
\text { Filamin-A } \\
\text { Proteasome activator complex subunit } 2 \\
\text { Heat shock protein HSP } 90-\beta\end{array}$ & $\begin{array}{l}2.691 \\
1.884 \\
1.430 \\
1.793 \\
1.321 \\
1.272\end{array}$ \\
\hline \multicolumn{2}{|l|}{ DNA replication initiation } \\
\hline $\begin{array}{l}\text { DNA replication licensing factor } \mathrm{MCM} 2 \text { (MCM2) } \\
\text { DNA replication licensing factor } \mathrm{MCM} 5 \\
\text { DNA replication licensing factor } \mathrm{MCM} 7\end{array}$ & $\begin{array}{l}1.549 \\
1.494 \\
1.419\end{array}$ \\
\hline \multicolumn{2}{|c|}{$\begin{array}{l}\text { Abbreviations: } \mathrm{EC}=\text { grade } 1 \text { endometrioid carcinoma; } \mathrm{HGSC}=\text { high-grade serous carci- } \\
\text { noma; } \mathrm{MCM} 2=\mathrm{DNA} \text { replication licensing factor minichromosome maintenance protein } 2 \text {. } \\
\text { Protein ontology analysis finds two enriched terms in HGSC: 'negative regulation of a } \\
\text { protein metabolic process' and 'DNA replication initiation'. Each term was organised } \\
\text { around six and three proteins, respectively. Respectively, IMP2 and MCM2 were the most } \\
\text { differentially expressed proteins for each term. Differential expression ratio was calculated } \\
\text { from the mean of protein expression values of HGSC /EC samples. }\end{array}$} \\
\hline
\end{tabular}

In order to identify the molecular features of gynaecological cancer, mRNA expression analyses have been performed (Kandoth et al, 2013). However, cDNA microarray analyses only assess differences at the mRNA level, and it is well known that mRNA levels do not necessarily correspond with protein levels, largely because of differentials in mRNA translation rates and protein half-lives (Chen et al, 2002; Tian et al, 2004). Therefore, the analysis of protein expression levels may identify biological features of gynaecological cancers not identifiable by solely mRNA analysis. Although the comprehensiveness and sensitivity of protein analysis is notably inferior to mRNA analysis, the data obtained from protein analysis are more directly related to the expression levels of identified proteins.

In clear cell carcinoma, similar gene expression patterns have been reported between renal, endometrial and ovarian clear cell carcinoma (Zorn et al, 2005). Zorn et al (2005) compared the gene expression profiles of ovarian and endometrial serous carcinomas using unsupervised hierarchical cluster analysis and they found no statistical similarity. However, their cluster analysis was somewhat limited because they compared only the differences between ovarian and endometrial serous carcinoma without including other histological types of ovarian and endometrial cancer, whereas our study compares the protein expression profiles of ovarian and endometrial HGSC with ovarian and endometrial EC (a common form of ovarian and endometrial cancer). To assess the similarity of histological types using cluster analysis beyond just the organ, gene and protein expression profiles should be analysed in samples from more than one organ.

Our data corroborate current theories related to carcinogenesis in ovarian and endometrial HGSCs. Respectively, STICs and EICs are considered to be the precursor lesions of ovarian and endometrial HGSCs (Sherman et al, 1992; Gross et al, 2010), and they originate from the epithelium of the tubal fimbria and endometrium, respectively, that are both derived from the fetal Müllerian duct. Furthermore, both lesions have been shown to have high expression levels of p53 and Ki-67 proteins (Levanon et al, 2008; Jarboe et al, 2009). These findings indicate that ovarian and endometrial HGSCs may develop from the epithelium of Müllerian duct-derived organs via similar tumourigenic molecular pathways.

We performed gene and protein ontology analysis to determine whether changes in groups of functionally related proteins were unique to gynaecological cancer. Ontology analysis is a bioinformatics tool allowing the identification and visualisation of enriched terms among groups of genes or proteins. Identification of enriched terms with biological relevance can select potential target 


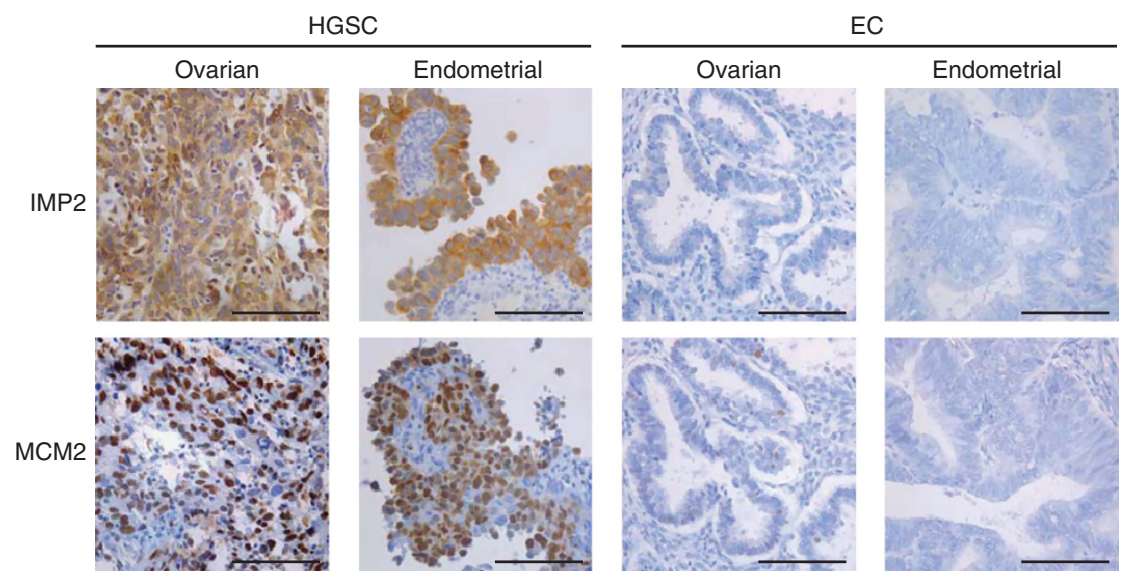

Figure 3. Immunohistochemical analysis of IMP2 and MCM2 expression. Intense IMP2 and MCM2 immunohistochemical staining is shown in HGSCs as compared with ECs. The IHC staining in tissue sections revealed significantly more intense IMP2 and MCM2 staining in HGSCs as compared with ECs $(P<0.01$ and $P<0.01$, respectively; see in Table 4). Scale bar, $100 \mu \mathrm{m}$.

Table 4. Immunohistochemical analysis of (a) IMP2 and (b) MCM2 expression in HGSCs and ECs

\begin{tabular}{|c|c|c|c|c|c|}
\hline \multirow[b]{2}{*}{ Organ } & \multicolumn{2}{|c|}{ HGSC } & \multicolumn{2}{|c|}{$\mathrm{EC}$} & \multirow[b]{2}{*}{$P$-value } \\
\hline & High & Low & High & Low & \\
\hline \multicolumn{6}{|l|}{ (a) IMP2 } \\
\hline Ovary & 39 (89\%) & $5(11 \%)$ & $2(11 \%)$ & $16(89 \%)$ & $<0.01$ \\
\hline Endometrium & 23 (79\%) & $6(21 \%)$ & 2 (15\%) & 11 (85\%) & $<0.01$ \\
\hline Total & $62(85 \%)$ & 11 (15\%) & $4(13 \%)$ & 27 (87\%) & $<0.01$ \\
\hline & & & & \multicolumn{2}{|c|}{ (Fisher's exact test) } \\
\hline \multicolumn{6}{|l|}{ (b) MCM2 } \\
\hline Ovary & $38(86 \%)$ & $6(14 \%)$ & $3(17 \%)$ & 15 (83\%) & $<0.01$ \\
\hline Endometrium & 24 (83\%) & 5 (17\%) & 1 (8\%) & 12 (92\%) & $<0.01$ \\
\hline Total & $62(85 \%)$ & $11(15 \%)$ & $4(13 \%)$ & 27 (87\%) & $<0.01$ \\
\hline & & & & \multicolumn{2}{|c|}{ (Fisher's exact test) } \\
\hline \multicolumn{6}{|c|}{$\begin{array}{l}\text { Abbreviations: } \mathrm{EC}=\text { grade } 1 \text { endometrioid carcinoma; } \mathrm{HGSC}=\text { high-grade serous carci- } \\
\text { noma; IMP2 }=\text { insulin-like growth factor } 2 \text { mRNA-binding protein } 2 ; \mathrm{MCM} 2=\mathrm{DNA} \\
\text { replication licensing factor minichromosome maintenance protein } 2 \text {. IHC staining of IMP2 } \\
\text { and MCM2 in tissue sections revealed significantly more intense IMP2 and MCM2 staining } \\
\text { in HGSCs as compared with ECs }(P<0.01 \text { ). Immunohistochemical }(\mathrm{IHC}) \text { scoring was } \\
\text { performed according to the intensity and distribution of positive staining. Slides were } \\
\text { scored as follows: } 0+\text {, no cells stained; } 1+\text {, pale staining observed in any cells; } 2+\text {, deeply } \\
\text { stained cells covering }<25 \% \text { of the total area; } 3+\text {, deeply stained cells covering } 25 \%-49 \% \\
\text { of the total area; or } 4+\text {, deeply stained cells covering }>50 \% \text { of the total area. Samples were } \\
\text { divided into the low expression group (samples with scores of } 0+, 1+\text { and } 2+\text { ) or the high } \\
\text { expression group (scores of } 3+\text { and } 4+\text { ). }\end{array}$} \\
\hline
\end{tabular}

proteins for the development of novel cancer therapies. In the present study, we have identified substantial differences in the expression of protein related to 'negative regulation of protein metabolic process' and 'DNA replication initiation' by protein ontology analysis. Six differentially expressed proteins were found to be involved in 'negative regulation of metabolic process' and three in 'DNA replication initiation'.

The IMP2 and MCM2 were the most differentially expressed proteins related to each term. We therefore evaluated the functions of IMP2 and MCM2 in HGSC. The IMP2 is an mRNA-binding protein located in the cytoplasm that has been implicated in several post-transcriptional processes of protein metabolism (Cleynen et al, 2007). In hepatocellular carcinoma, IMP2 has an independent anti-apoptotic function dependent on ERK1/2 phosphorylation (independently of IGF2/PI3K) (Kessler et al, 2013). In gynaecological cancer, IMP2 has been shown to be highly expressed in endometrial HGSC and it has potential as a differential diagnostic marker for other histological endometrial cancer types as well (Zhang et al, 2011). Our data demonstrate that IMP2 is highly expressed not only in ovarian and endometrial HGSCs, but also in tubal and peritoneal HGSCs. We have demonstrated that knockdown of IMP2 protein expression in ovarian HGSC cell line significantly induced G0/G1 cell cycle arrest, resulting in a decreased population of S-phase cells and reduced cell proliferation. These findings indicate that high levels of IMP2 expression may contribute to the rapid cell proliferation and tumour growth of HGSC observed clinically.

The other protein of great interest, MCM2, is one of six proteins (MCM 2-7) that comprise the MCM helicase complex involved in the regulation of the $S$ phase of the cell cycle in eukaryotes via the initiation of DNA replication (Kang et al, 2014). High MCM2 expression is reportedly a poor prognostic factor in ovarian cancer (Gakiopoulou et al, 2007). Furthermore, another member of the MCM2 family, MCM7, is reportedly a particularly poor prognostic factor in ovarian HGSC (Ota et al, 2011). In the present study, MCM2 was found to be differentially expressed in tubal and peritoneal HGSCs in addition to ovarian and endometrial HGSCs. Our data further demonstrate that knockdown of MCM2 expression in ovarian HGSC cell line significantly decreased the rate of cellular proliferation. These findings indicate that not only could IMP2 and MCM2 be good potential diagnostic markers for pelvic HGSC but also that they contribute directly to the rapid growth of HGSC observed clinically.

We identified $\sim 1000$ proteins as compared with over 10000 expressed mRNAs identifiable using cDNA microarrays. Some small number of important proteins are therefore likely to have been omitted in our analysis; however, these ultralow expressed proteins are far less likely to contribute to the major histological and molecular features of HGSC than the moderately to highly expressed proteins identified in the present study.

The phosphorylation of proteins by protein kinases, known to play a pivotal role in the functional regulation of protein activity, was not investigated in the present study. The aim of the present study was to evaluate the statistical similarity of protein expression profiles between ovarian and endometrial HGSCs; however, the future determination of the phosphorylation status of the major proteins related to HGSCs may reveal additional molecular features of HGSCs.

In summary, we have performed protein expression profiling of ovarian and endometrial HGSCs using exhaustive and quantitative proteomic analysis. Using an unsupervised hierarchical cluster analysis, we have demonstrated the statistical similarity between ovarian and endometrial HGSCs beyond the organs using unsupervised hierarchical cluster analysis. In the past, decisions regarding the clinical management of gynaecological cancers, including staging and treatment, were predominantly, if not exclusively, based on the organs of tumour. However, the findings 
A
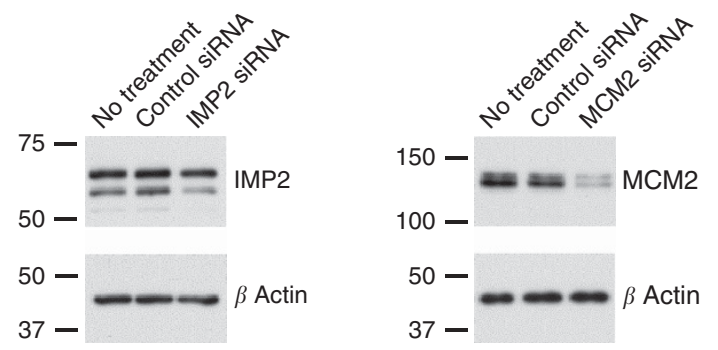

B
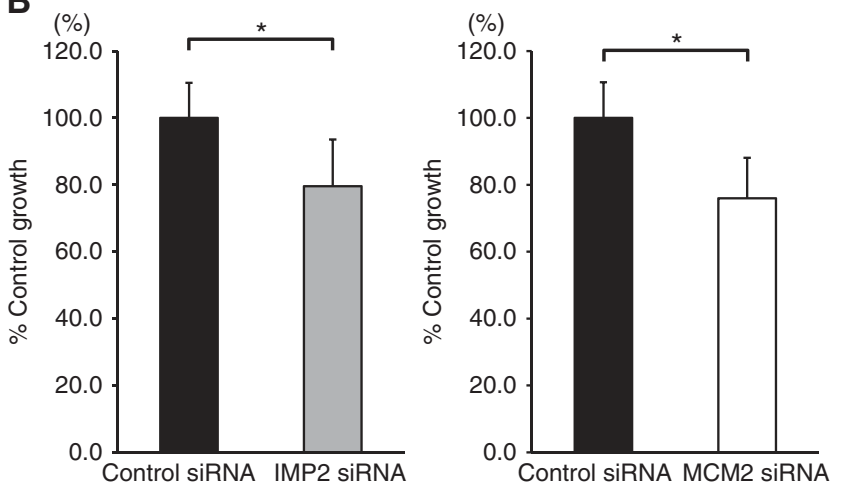

C

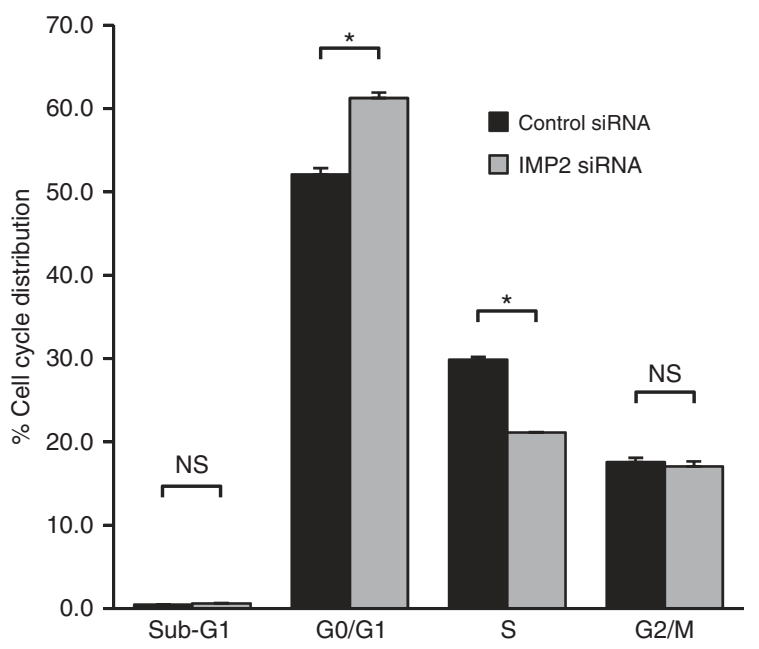

Figure 4. Functional analysis of IMP2 and MCM2. (A) Western blotting demonstrating similar silencing effects of IMP2 siRNA and MCM2 siRNA on protein expression levels of IMP2 and MCM2, respectively, in KURAMOCHI cells. (B) Cell proliferation assays demonstrated significantly reduced cellular proliferation following transfection of KURAMOCHI cells with IMP2 siRNA and MCM2 siRNA as compared with control siRNA ( $\left.{ }^{*}<<0.01\right)$. (C) Cell cycle assay demonstrated significantly increased G0/G1 and decreased S-phase cell populations following transfection of KURAMOCHI cells with IMP2 siRNA as compared with control siRNA ( $\left.{ }^{\star} P<0.01\right)$.

of our cluster and ontology analyses of different organ sources of HGSCs demonstrate that the tumour's histological type is a major contributing factor to its molecular characteristics. The classification of HSGC tumours according to histological examination may have greater utility in determining the most appropriate treatment approaches than simply relying on the organ.

\section{ACKNOWLEDGEMENTS}

We thank A Yagi for secretarial assistance, K Sakiyama for technical assistance and Dr GS Buzard for editorial assistance.
This research was supported by the JSPS KAKENHI Grant (number 25293338) from the Ministry of Education, Culture, Sports, Science and Technology.

\section{CONFLICT OF INTEREST}

The authors declare no conflict of interest.

\section{REFERENCES}

Ab Mutalib NS, Syafruddin SE, Md Zain RR, Mohd Dali AZ, Mohd Yunos RI, Saidin S, Jamal R, Mokhtar NM (2014) Molecular characterization of serous ovarian carcinoma using a multigene next generation sequencing cancer panel approach. BMC Res Notes 7: 805.

Cao QJ, Belbin T, Socci N, Balan R, Prystowsky MB, Childs G, Jones JG (2004) Distinctive gene expression profiles by cDNA microarrays in endometrioid and serous carcinomas of the endometrium. Int J Gynecol Pathol 23(4): 321-329.

Chen G, Gharib TG, Huang CC, Taylor JM, Misek DE, Kardia SL, Giordano TJ, Iannettoni MD, Orringer MB, Hanash SM, Beer DG (2002) Discordant protein and mRNA expression in lung adenocarcinomas. $\mathrm{Mol}$ Cell Proteomics 1(4): 304-313.

Cleynen I, Brants JR, Peeters K, Deckers R, Debiec-Rychter M, Sciot R, Van de Ven WJ, Petit MM (2007) HMGA2 regulates transcription of the Imp2 gene via an intronic regulatory element in cooperation with nuclear factor-kappaB. Mol Cancer Res 5(4): 363-372.

del Carmen MG, Birrer M, Schorge JO (2012) Uterine papillary serous cancer: a review of the literature. Gynecol Oncol 127(3): 651-661.

Gakiopoulou H, Korkolopoulou P, Levidou G, Thymara I, Saetta A, Piperi C, Givalos N, Vassilopoulos I, Ventouri K, Tsenga A, Bamias A, Dimopoulos MA, Agapitos E, Patsouris E (2007) Minichromosome maintenance proteins 2 and 5 in non-benign epithelial ovarian tumours: relationship with cell cycle regulators and prognostic implications. Br J Cancer 97(8): 1124-1134.

Gross AL, Kurman RJ, Vang R, Shih IeM, Visvanathan K (2010) Precursor lesions of high-grade serous ovarian carcinoma: morphological and molecular characteristics. J Oncol 2010: 126295.

Huang da W, Sherman BT, Lempicki RA (2009) Systematic and integrative analysis of large gene lists using DAVID bioinformatics resources. Nat Protoc 4(1): 44-57.

Iwahori K, Serada S, Fujimoto M, Nomura S, Osaki T, Lee CM, Mizuguchi H, Takahashi T, Ripley B, Okumura M, Kawase I, Kishimoto T, Naka T (2011) Overexpression of SOCS3 exhibits preclinical antitumor activity against malignant pleural mesothelioma. Int J Cancer 129(4): 1005-1017.

Jarboe EA, Miron A, Carlson JW, Hirsch MS, Kindelberger D, Mutter GL, Crum CP, Nucci MR (2009) Coexisting intraepithelial serous carcinomas of the endometrium and fallopian tube: frequency and potential significance. Int J Gynecol Pathol 28(4): 308-315.

Kandoth C, Schultz N, Cherniack AD, Akbani R, Liu Y, Shen H, Robertson AG, Pashtan I, Shen R, Benz CC, Yau C, Laird PW, Ding L, Zhang W, Mills GB, Kucherlapati R, Mardis ER, Levine DA (2013) Integrated genomic characterization of endometrial carcinoma. Nature 497(7447): 67-73.

Kang S, Warner MD, Bell SP (2014) Multiple functions for Mcm2-7 ATPase motifs during replication initiation. Mol Cell 55(5): 655-665.

Kannan K, Coarfa C, Chao PW, Luo L, Wang Y, Brinegar AE, Hawkins SM, Milosavljevic A, Matzuk MM, Yen L (2015) Recurrent BCAM-AKT2 fusion gene leads to a constitutively activated AKT2 fusion kinase in high-grade serous ovarian carcinoma. Proc Natl Acad Sci USA 112(11): E1272-E1277.

Kessler SM, Pokorny J, Zimmer V, Laggai S, Lammert F, Bohle RM, Kiemer AK (2013) IGF2 mRNA binding protein p62/IMP2-2 in hepatocellular carcinoma: antiapoptotic action is independent of IGF2/PI3K signaling. Am J Physiol Gastrointest Liver Physiol 304(4): G328-G336.

Kondo T, Hirohashi S (2006) Application of highly sensitive fluorescent dyes (CyDye DIGE Fluor saturation dyes) to laser microdissection and two-dimensional difference gel electrophoresis (2D-DIGE) for cancer proteomics. Nat Protoc 1(6): 2940-2956.

Kurman RJ (2013) Origin and molecular pathogenesis of ovarian high-grade serous carcinoma. Ann Oncol 24(Suppl 10): x16-x21. 
Levanon K, Crum C, Drapkin R (2008) New insights into the pathogenesis of serous ovarian cancer and its clinical impact. J Clin Oncol 26(32): 5284-5293.

Macoska JA (2002) The progressing clinical utility of DNA microarrays. CA Cancer J Clin 52(1): 50-59.

Malpica A, Deavers MT, Lu K, Bodurka DC, Atkinson EN, Gershenson DM, Silva EG (2004) Grading ovarian serous carcinoma using a two-tier system. Am J Surg Pathol 28(4): 496-504.

Ota T, Clayton AC, Minot DM, Shridhar V, Hartmann LC, Gilks CB, Chien JR (2011) Minichromosome maintenance protein 7 as a potential prognostic factor for progression-free survival in high-grade serous carcinomas of the ovary. Mod Pathol 24(2): 277-287.

Pathiraja P, Dhar S, Haldar K (2013) Serous endometrial intraepithelial carcinoma: a case series and literature review. Cancer Manag Res 5: $117-122$.

Salvador S, Rempel A, Soslow RA, Gilks B, Huntsman D, Miller D (2008) Chromosomal instability in fallopian tube precursor lesions of serous carcinoma and frequent monoclonality of synchronous ovarian and fallopian tube mucosal serous carcinoma. Gynecol Oncol 110(3): 408-417.

Santin AD, Zhan F, Bellone S, Palmieri M, Cane S, Gokden M, Roman JJ, O’Brien TJ, Tian E, Cannon MJ, Shaughnessy Jr J, Pecorelli S (2004) Discrimination between uterine serous papillary carcinomas and ovarian serous papillary tumours by gene expression profiling. $\mathrm{Br} J$ Cancer 90(9): 1814-1824.

Sherman ME, Bitterman P, Rosenshein NB, Delgado G, Kurman RJ (1992) Uterine serous carcinoma. A morphologically diverse neoplasm with unifying clinicopathologic features. Am J Surg Pathol 16(6): 600-610.

Soslow RA, Bissonnette JP, Wilton A, Ferguson SE, Alektiar KM, Duska LR, Oliva E (2007) Clinicopathologic analysis of 187 high-grade endometrial carcinomas of different histologic subtypes: similar outcomes belie distinctive biologic differences. Am J Surg Pathol 31(7): 979-987.

Tian Q, Stepaniants SB, Mao M, Weng L, Feetham MC, Doyle MJ, Yi EC, Dai H, Thorsson V, Eng J, Goodlett D, Berger JP, Gunter B, Linseley PS, Stoughton RB, Aebersold R, Collins SJ, Hanlon WA, Hood LE (2004) Integrated genomic and proteomic analyses of gene expression in Mammalian cells. Mol Cell Proteomics 3(10): 960-969.

Yokoyama T, Enomoto T, Serada S, Morimoto A, Matsuzaki S, Ueda Y, Yoshino K, Fujita M, Kyo S, Iwahori K, Fujimoto M, Kimura T, Naka T (2013) Plasma membrane proteomics identifies bone marrow stromal antigen 2 as a potential therapeutic target in endometrial cancer. Int J Cancer 132(2): 472-484.

Zhang L, Liu Y, Hao S, Woda BA, Lu D (2011) IMP2 expression distinguishes endometrioid from serous endometrial adenocarcinomas. Am J Surg Pathol 35(6): 868-872.

Zheng W, Schwartz PE (2005) Serous EIC as an early form of uterine papillary serous carcinoma: recent progress in understanding its pathogenesis and current opinions regarding pathologic and clinical management. Gynecol Oncol 96(3): 579-582.

Zorn KK, Bonome T, Gangi L, Chandramouli GV, Awtrey CS, Gardner GJ, Barrett JC, Boyd J, Birrer MJ (2005) Gene expression profiles of serous, endometrioid, and clear cell subtypes of ovarian and endometrial cancer. Clin Cancer Res 11(18): 6422-6430.

This work is published under the standard license to publish agreement. After 12 months the work will become freely available and the license terms will switch to a Creative Commons AttributionNonCommercial-Share Alike 4.0 Unported License.

Supplementary Information accompanies this paper on British Journal of Cancer website (http://www.nature.com/bjc) 